\title{
Modified Non-Linear Control for Microgrid Photovoltaic Power System
}

\author{
Sharon S. Gerang, Muhammad A. Osman, and Naeem M.S. Hannoon
}

\begin{abstract}
This paper presents a Modified Non-Linear Control (MNLC) for microgrid to optimize the performances of microgrid photovoltaic systems during outages/disturbance in distributed generation. This system underlines the adequacy of this proposed control methodology in terms of power management and stability of the system under various scenarios which are solar irradiance, man-made fault, etc.All these scenarios are presented during high loading conditions. This proposed non-linear control is tested at both point of common coupling (PCC) and the receiving end during sudden change of load. The simulated results are compared with PI controller using a software platform, MATLAB, Simulink. The system consists of a photovoltaic (PV) arrays, a DC-DC boost converter, a maximum power point tracker (MPPT) controller, wind turbine, battery and a resistive-inductive load. To validate the performance of the proposed MNLC over conventional designs the PV based Microgrid is subjected to grid side contingency (i.e. dynamic Load variation), as well as distributed generation (dg) side uncertainty (i.e. Partial shading). The performance of proposed MNLC is evidenced effective in MATLAB Simulink environment.
\end{abstract}

Index Terms-PV Array, MPPT, PI Controller, Modified NonLinear Control, Simulink

\section{INTRODUCTION}

$\mathrm{P}$ attern of generation and consumption for electricity change due to the reduction of environmental pollution. Reduction of environmental pollution caused by electricity production with reliable and efficient supply of electricity has instigated the research towards microgrids. A microgrid is composed of distributed generations, loads, energy storage, secondary loads and controllers which cover the electrification of a small geographical area and can be operated in gridconnected mode as well as islanded mode. Compared to the traditional grid, the microgrid has various stability issues due to unpredictable renewable sources and highly fluctuating demand [1].

Standard proportional-integral (PI) based feedback designs have implemented effectively for last fifty years [19] and utilized rigorously for industrial converter control till date. The primary cause of that is because of their less operational complexity, simple architecture, economical maintenance, and effectiveness for most grid tied converters (bounded uncertainties to be handled with).

This manuscript is submitted on $8^{\text {th }}$ April 2020 and accepted on $14^{\text {th }}$ September 2020. Sharon Serenade Anak Gerang, Muhd Amirul Osman and Naeem M.S Hannon and are with the Faculty of Electrical Engineering, Universiti Teknologi MARA, 40450 Shah Alam, Selangor (e-mail: sharon.serenade94@gmail.com)

1985-5389/C 2021 The Authors. Published by UiTM Press. This is an open access article under the CC BY-NC-ND license (http://creativecommons.org/ licenses/by-nc-nd/4.0/).
Lately, inspired by the escalated development of advance microcontrollers and digital signal processors, conventional PI based converter control gets high importance in renewable market, from DGs' feedback controllers to battery charge controllers $[19,20]$.

The recent years exhibit research trends in renewable energy management, self-sufficient local area micro-generation and power flow analysis of distributed generation sources. The huge increase of grid-connected PV generation system can pose serious challenges to maintain grid stability, power quality, power mismatch, power control, energy management and also efficient protection tasks, etc. [2-3]. Various power flow control strategies for three-phase grid-connected PV systems have been reported in the literature [4-7]. In [7], dynamic modeling of PV systems has been carried out for designing appropriate interfacing circuits and controllers for practical PV systems and to investigate transient responses with change in solar irradiance and operating temperature. The connection of the PV array to the grid is usually made with a voltage source converter (VSC), and it may include intermediate dc-dc converter, a transformer, or even both. It has been reported that high bandwidth grid active and reactive power control is achieved by directly controlling the currents of the VSC. Most of the controllers belong to either PI controllers or hysteresis band type controllers. The controllers are implemented in synchronously rotating reference d-q frame using PI controller or stationery abc reference frame using proportional resonant (PR) controller. A predictive controller based current control scheme implemented in synchronously rotating reference frame is proposed in [8]. Further the PI controllers are designed by trial and error and their performance deteriorates with the changing of the operating conditions. Besides the PI controller, several other linear and nonlinear controllers have been reported for active and reactive power flow control in the PV inverters [9-11] using dq current components as dynamic variables.

PV based DGs are also well cited with PI based feedback path against grid PLL operation [19, 21]. Although, these PI based controllers normally unable to perform under unbounded uncertainties (e.g. PV side contingencies: partial shading; grid side contingencies: islanding condition etc.), especially for higher order (fractional derivative relation based VSC) and time-delayed dynamic systems (VSC operation with Primary Controllers: PCs). To cope with these challenges different improvements are incorporated to conventional PI design. Auto-tuning operation and adaptive PI based feedback paths are 
recently added to literature [22]. Further new types of PI based Independent DG Controllers (IDGCs) with Fuzzy Logic (FL) is implemented for DG PLL [23].

\section{Dynamic Model of PhOtovoltaic}

Solar cell is a $p$-n junction fabricated in a thin wafer of semiconductor. In addition, the electromagnetic radiation of solar energy can be directly converted to electricity through photovoltaic effect. Photons with energy greater than the bandgap energy of the semiconductor that being exposed to the sunlight, creates some electron-hole pairs proportional to the occurrence irradiation [12].

$\mathrm{I}_{\mathrm{L}}$ is the current source, represents the cell photocurrent. Rsh and Rs are the inherent shunt and series resistances of the cell, severally. The value of Rsh usually come out with a large compared with Rs which is exceedingly small, hence they may be deteriorated to simplify the analysis.

PV modules that grouped by the larger units of PV cells which are further interconnected in a parallel-series arrangement to form PV arrays. The equations of photovoltaic panel model are given in equations (1)-(6).

The issues of reactive power are come whenever there is no irradiance and no temperature at all [16]. The real power will drop to zero when the reactive power is high. The controller of inverter will be remunerated during for example at night that can cause current lead the voltage [17]. The control design is prior to such implementation in grid connected power system operation. By proper control architecture by following equations, the power quality is to be maintained for such DG integrated operations, without grid instability/ failure under normal operating/ balanced condition. The linear controllers (e.g. Proportional-Integral/ PI controller) are not effective under increased contingencies due to DG integration to existing utility grid. This is majorly due to the requirement of bidirectional power flow under both grid side (e.g. short-circuit faults, islanding) as well as DG side (e.g. renewable energy inconsistencies like: solar irradiation variation, partial shading) contingencies. Thus, non-linear controllers are well cited in literature against such DG integrated grid/ microgrid operation.

The conventional non-linear controller like Fuzzy -PI based feedback path for PV based DG integration is quite successful in terms of industrial implementations. The major disadvantage is due to the predefined/ pre-studied Fuzzy rule base, which makes them system dependent performer. But in recent studies it has been highlighted that the performance deteriorates within a range depending on implementation. Thus, in proposed Fuzzy-PI control-based feedback path design an adaptive nature is incorporated by metaheuristic algorithm, so that the fuzzy rules are getting adaptive within that same range of error variations. This work is quite interesting in terms of PV based DG implementation for any active distribution networks. The controller is studied quite promising in terms of reduction in dynamic oscillation cycles after contingencies are cleared.

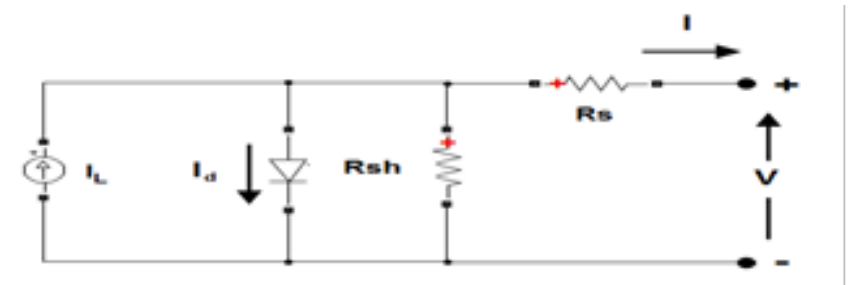

Fig. 1. Photovoltaic Circuit

The equivalent circuit of a PV cell is as shown in Fig. 1.

Equation for this equivalent circuit is formulated using Kirchhoff's current law for current I

$$
I=I_{L}-I_{D}-I_{S h}
$$

Here, IL represents the light-generated current in the cell, $I_{t}$ represents the voltage-dependent current lost to recombination, and $\mathrm{I}_{\mathrm{sh}}$ represents the current lost due to shunt resistances. In this single diode model, $I_{D}$ is modeled using the Shockley equation for an ideal diode:

$$
I_{D}=I_{o}\left[\exp \left(\frac{V+I R_{S}}{n V_{T}}\right)-1\right]
$$

Where $n$ is the diode ideality factor (unit less, usually between 1 and 2 for a single junction cell), Iois the saturation current, and $\mathrm{V}_{\mathrm{T}}$ is the thermal voltage given by:

$$
V_{T}=\frac{k T_{c}}{q}
$$

Where $\mathrm{k}$ is Boltzmann's constant $\left(1.381 \times 10^{-23} \mathrm{~J} / \mathrm{K}\right)$ and $\mathrm{q}$ is the elementary charge $\left(1.602 \times 10^{-19} \mathrm{C}\right)$.

Writing the shunt current as $\mathrm{I}_{\mathrm{sh}}=(\mathrm{V}+\mathrm{IRs}) / \mathrm{R}_{\mathrm{sh}}$ and combining this and the above equations results in the complete governing equation for the single diode model:

$$
I=I_{L}-I_{0}\left[\exp \left(\frac{V+I R_{S}}{n V_{T}}\right)-1\right]-\frac{V+I R_{S}}{R_{s h}}
$$

Where:

$\mathrm{I}_{\mathrm{L}}$ : Light Current (A)

Io: Diode Reverse Saturation Current (A)

$\mathrm{R}_{\mathrm{S}}$ : Series Resistance $(\Omega)$

$\mathrm{R}_{\text {sh }}$ : Shunt Resistance $(\Omega)$

n: Diode Ideality Factor

Saturation current Io varies with the cell temperature, which is given by

$$
I=I_{r s}\left[\frac{T}{T_{r}}\right]^{3} \exp \left[\frac{q^{*} E_{g 0}}{B k}\left\{\frac{1}{T_{r}}-\frac{1}{T}\right\}\right]
$$

The current output of PV module is 


$$
\begin{aligned}
I_{p v}=N_{p} x I_{p h}- & N_{p} x I_{o}\left[\operatorname { e x p } \left\{\frac{q x\left(V_{p v}+I_{p v} R_{s}\right.}{N_{s} A k T}\right.\right. \\
-1 &
\end{aligned}
$$

The elemental unit of PV system is PV cell, irrespective of the utilization. The output voltage of a single PV cell is low (around 0.5 volts). Thus, in pragmatic application, these basic units are combined in number of parallel cells $(\mathrm{Np})$ and series cells (Ns) to obtain the output current (Ipv) function of the PV array, as mentioned.

$$
I_{p v}=N p[I p h-I r s(\operatorname{expaVpv-1)}]
$$

Where:

$$
\alpha=\frac{q}{N_{s} x T x k x a}
$$

$\mathrm{q}=1.602 \times 10-19 \mathrm{C}$

$\mathrm{k}=1.38 \times 10-23 \mathrm{~J} / \mathrm{K}$

Iph is photo current, generated by photon insolation is derived as:

$$
I p h=0.01 \times G x[I s c+k i(T *-T)]
$$

Where $\mathrm{G}$ is called as irradiance Watt $/ \mathrm{m} 2$

$\mathrm{ki}=0.015$

Reverse saturation current (Irs) of the diode from the equivalent circuit of $\mathrm{PV}$ cell is estimated as shown:

$$
I_{r s}=I_{r r}\left[\frac{T}{T^{\phi}}\right]^{2} \exp \left[\frac{q x E_{g}}{k x a}\left\{\frac{1}{T_{r}}-\frac{1}{T^{\phi}}\right\}\right]
$$

Where Eg is band gap energy of the semiconductor material of the cell.

Derivative of PV power by the voltage is equal to zero. Accordingly, at the maximum power point:

$$
\begin{gathered}
\frac{d P_{p v}}{d V_{p v}}=N_{p}\left[I_{p h}-I_{r s}\left(V_{p v} x \exp ^{\alpha V_{p v}}+\exp ^{\alpha V_{p v}}\right.\right. \\
-1)]=0
\end{gathered}
$$

The step size (Ov) is reduced and accurate the tracking as it reaches nearer to the MPP point:

$$
O v=N * a b s\left(\frac{d P p v}{d V p v}\right)
$$

VSC dynamic model in abc reference frame is obtained as:

$$
V_{i . a b c}=L_{i} \frac{d I_{i . a b c}}{d_{t}}+R_{i} I_{i . a b c}+V_{2 . a b c}
$$

Where,

$\mathrm{Vi}, \mathrm{abc}=$ voltage at ac side of the VSC

$\mathrm{V} 2, \mathrm{abc}=$ voltage at PCC

$\mathrm{Ii}, \mathrm{abc}=$ instantaneous current at $\mathrm{abc}$
After transformation of equation (5) from abc reference frame to dq reference frame the VSC dynamic equations become [13]:

$$
\begin{aligned}
& \frac{d I_{i d}}{d_{t}}=-\frac{R_{i}}{L_{i}} I_{i d}+\omega I_{i q}+\frac{V_{i d}+V_{2 d}}{L_{i}} \\
& \frac{d I_{i q}}{d_{t}}=-\frac{R_{i}}{L_{i}} I_{i q}+\omega I_{i d}+\frac{V_{i q}+V_{2 q}}{L_{i}}
\end{aligned}
$$

Where:

$\mathrm{Vi}, \mathrm{dq}=$ voltage at ac side of the VSI

$\mathrm{V} 2, \mathrm{dq}=$ voltage at the PCC

$\mathrm{Ii}, \mathrm{dq}=$ instantaneous current in $\mathrm{dq}$ frame.

$$
\begin{aligned}
& V i d=\frac{\sqrt{3}}{2 \sqrt{2}} V p v(\operatorname{macos} 6)=\frac{\sqrt{3}}{2 \sqrt{2}} \operatorname{Vpvud}, \\
& V i q=\frac{\sqrt{3}}{2 \sqrt{2}} \operatorname{Vpv}(\operatorname{masin} 6)=\frac{\sqrt{3}}{2 \sqrt{2}} \operatorname{Vpvuq}
\end{aligned}
$$

Where:

$\mathrm{ud}=(\mathrm{ma} \cos 6)$

$\mathrm{uq}=(\operatorname{ma} \sin 6)$,

$\mathrm{Vpv}=$ voltage at PV side of VSI

$\mathrm{Ma}=\mathrm{PWM}$ modulation index

$6=$ phase angel for firing of IGBTs of VSI inverter

The active and reactive powers at the PCC in the abc reference frame are obtained as:

$$
\begin{aligned}
P_{2}=\frac{3}{2}\left(V_{2 d} I_{i d}+V_{2 q} I_{i q}\right) & \\
= & \left(V_{2 a} I_{i a}+V_{2 b} I_{i b}+V_{2 c} I_{i c}\right) \\
Q_{2}=\frac{3}{2}\left(V_{2 d} I_{i d}\right. & \left.+V_{2 q} I_{i q}\right) \\
& =\frac{1}{\sqrt{3}}\left[V_{2 a}\left(I_{i b}-I_{i c}\right)\right. \\
& +V_{2 b}\left(I_{i c}-I_{i a}\right) \\
& \left.+V_{2 c}\left(I_{i a}-I_{i b}\right)\right]
\end{aligned}
$$

Only to design the ultimate control theory by calculating control variables, a $d-q$ axis power-based description of VSC dynamics is presented. The instantaneous active power $\left(P_{2}\right)$ and reactive power $\left(Q_{2}\right)$ at PCC in $d-q$ reference frame:

$$
\begin{aligned}
& P_{2}=\frac{3}{2}\left(V_{2 d} I_{i d}+V_{2 q} I_{i q}\right), \\
& Q_{2}=\frac{3}{2}\left(V_{2 q} I_{i d}+V_{2 d} I_{i q}\right)
\end{aligned}
$$

From equation (18), the instantaneous currents are obtained as:

$$
\begin{aligned}
I_{i d}=\frac{2}{3}\left(\frac{P_{2} V_{2 d}+Q_{2} V_{2 q}}{V_{2}{ }^{2}}\right) I_{i q} \\
=\frac{2}{3}\left(\frac{P_{2} V_{2 q}+Q_{2} V_{2 d}}{V_{2}{ }^{2}}\right)
\end{aligned}
$$


The voltage components $2 \mathrm{~d}, \mathrm{~V} 2 \mathrm{q}$ and Iid, Iiq are obtained from the phase voltage and current components in the stationary frame as:

$$
\begin{aligned}
& V_{2 d}=\left(\frac{1}{\sqrt{3}}\right)\left(V_{2 b}-V_{2 c}\right), I_{i d}=\left(\frac{1}{\sqrt{3}}\right)\left(I_{i b}-I_{i c}\right), \\
& V_{2 q}=\left(\frac{2}{3}\right) V_{2 a}-\left(\frac{1}{3}\right)\left(V_{2 b}+V_{2 c}\right) \\
& I_{i q}=\left(\frac{2}{3}\right) I_{i a}-\left(\frac{1}{3}\right)\left(I_{i b}-I_{i c}\right)
\end{aligned}
$$

By substituting these $I_{i d}$ and $I_{i q}$ values to equations (13) and (14), the following differential equations are obtained in terms of $P_{2}$ and $Q_{2}$ as:

$$
\begin{aligned}
& \frac{\mathrm{dP}_{2}}{\mathrm{~d}_{\mathrm{t}}}=-\frac{\mathrm{R}_{\mathrm{i}}}{\mathrm{L}_{\mathrm{i}}} P_{2}-\omega Q_{2}+\frac{U_{q}}{L_{i}} \\
& \frac{\mathrm{dQ}_{2}}{\mathrm{~d}_{\mathrm{t}}}=-\frac{\mathrm{R}_{\mathrm{i}}}{\mathrm{L}_{\mathrm{i}}} Q_{2}-\omega P_{2}+\frac{U_{q}}{L_{i}}
\end{aligned}
$$

where the control parameters are:

$$
\begin{gathered}
U_{q}=\left(\frac{3}{2}\right)\left[V_{i d} V_{2 d}+V_{i q} V_{2 q}-\left(V_{2 d}{ }^{2}+V_{2 q}{ }^{2}\right)\right] \\
U_{p}=\left(\frac{3}{2}\right)\left[V_{i d} V_{2 q}+V_{i q} V_{2 d}\right]
\end{gathered}
$$

At the PV side of the VSC, the dc link capacitor voltage shows another dynamic relation as (where switching losses is assumed to be neglected):

$$
C_{p v} \frac{d V_{p v}}{d_{t}}=I_{p v}-\frac{P_{i}}{V_{p v}}
$$

Which can be rewritten as:

$$
\frac{d V_{p v}}{d_{t}}=\frac{1}{C_{p v} V_{p v}}\left(P_{p v}-P_{i}\right)
$$

Equations (22), (23) and (27) are used to construct the dynamic model for the proposed VSC based grid integrated PV system. The operating frequency is attained during system dynamic operation by a droop control strategy as shown in equation (28).

$$
f-f 0=-R d r o o p(P i-P p v)
$$

Where $f 0=$ nominal operating frequency.

For the controller design power components are independent of abc to $d-q$ coordinate transformation [14]. To calculate the power components directly from abc coordinate voltage and current at PCC, equation (16) and (17) is considered. For PI controller small signal stability analysis, the method is outlined below:

Small signal stability analysis for Multivariable VSC model. In time domain, the VSC dynamics can be represented in small signal terms as:

$$
\begin{aligned}
& \frac{d \Delta V_{2}(t)}{d_{t}}=\frac{R_{i}}{L_{i}} \Delta P_{2}(t)-\omega \Delta Q_{2}(t)+\Delta U_{q}(t) \\
& \frac{d \Delta Q_{2}(t)}{d_{t}}=\frac{R_{i}}{L_{i}} \Delta Q_{2}(t)-\omega \Delta P_{2}(t)+\Delta U_{p}(t)
\end{aligned}
$$

Above two equations can be transformed in frequency domain and rewritten as:

$$
\begin{aligned}
& \left(s+\frac{R_{i}}{L_{i}}\right) \Delta P_{2}(s)+\omega \Delta Q_{2}(s)=\Delta U_{q}(s) \\
& -\omega \Delta P_{2}(s)+\left(s+\frac{R_{i}}{L_{i}}\right) \Delta Q_{2}(s)=\Delta U_{p}(s)
\end{aligned}
$$

The matrix representation of equations (31) and (32) is obtained as:

$$
\begin{gathered}
{\left[\begin{array}{l}
\Delta P_{2} \\
\Delta Q_{2}
\end{array}\right]=\left[\begin{array}{cc}
\frac{a_{1}}{a_{1}^{2}+a_{2}^{2}} & \frac{a_{2}}{a_{1}^{2}+a_{2}^{2}} \\
\frac{a_{2}}{a_{1}^{2}+a_{2}^{2}} & \frac{a_{1}}{a_{1}^{2}+a_{2}^{2}}
\end{array}\right]\left[\begin{array}{c}
\Delta U_{q} \\
\Delta U_{p}
\end{array}\right]} \\
\text { Where, } a_{1}=\left(s+\frac{R_{i}}{L_{i}}\right) \text { and } a_{2}=\omega
\end{gathered}
$$

Equation (33) represents a multivariable dynamic model as described in [15]. From equation (33) for active power control only, we can write:

$$
\Delta P_{2}=\frac{a_{1}}{a_{1}^{2}+a_{2}^{2}} \Delta U_{q}
$$

From the PI control design, it can be derived:

$$
\begin{aligned}
\left(\Delta P_{2}{ }^{\phi}-\Delta P_{2}\right)[ & \left.K_{p 1}+\frac{K_{i 1}}{S}\right] \\
& +K_{p v}\left(\Delta V_{p v} \phi-\Delta V_{p v}\right)=\Delta U_{q}
\end{aligned}
$$

On substitution and simplification, the following equation is obtained:

$$
\begin{aligned}
\Delta P_{2}=\frac{G_{11} G_{p 1}}{1+G_{11} G_{p 1}} & \Delta P_{2}{ }^{\phi} \\
& +\frac{G_{11} K_{p v}}{1+G_{11} G_{p 1}}\left(\Delta V_{p v}{ }^{\phi}\right. \\
& \left.-\Delta V_{p v}\right)
\end{aligned}
$$


The gains have been determined to minimum overshoot which ensures the stability. The frequency response has been analyzed to validate above mentioned stability of the closed loop path. By letting $s=j c_{s}$ the open loop SISO transfer function $G_{11}(s)$. $G p_{1}(s)$ is mapped into equation (37).

$$
\begin{aligned}
& G_{11}\left(j \omega_{s}\right) G_{p 1}\left(j \omega_{s}\right) \\
& =\frac{\left(b_{1} b_{2}-b_{3} b_{4}\right)+j\left(b_{3} b_{2}-b_{1} b_{4}\right)}{b_{2}{ }^{2}-b_{4}{ }^{2}}
\end{aligned}
$$

Where:

$$
\begin{gathered}
b_{1}=\frac{K_{i 1} R_{i}}{L_{i}-K_{p 1} \omega^{2}} \\
b_{2}=\left(R_{i} / L_{i}\right)^{2}+\omega_{s}^{2}+\omega^{2} \\
b_{3}=\frac{K_{i 1}+K_{p 1} R_{i}}{L_{i}} \\
b_{4}=2\left(R_{i} / L_{i}\right) \omega
\end{gathered}
$$

\section{MEthodology}

\section{Conventional Controller}

Output power equals to the sum of proportion and integration coefficients. The higher the proportion coefficient, the less the output power at the same control error. The higher the integration coefficient, the slower the accumulated integration coefficient. PI control provides zero control error and is insensitive to interference of the measurement channel. The PI control disadvantage is slow reaction to disturbances. To adjust the conventional controller should first set the integration time equal to zero, and the maximum proportion time.

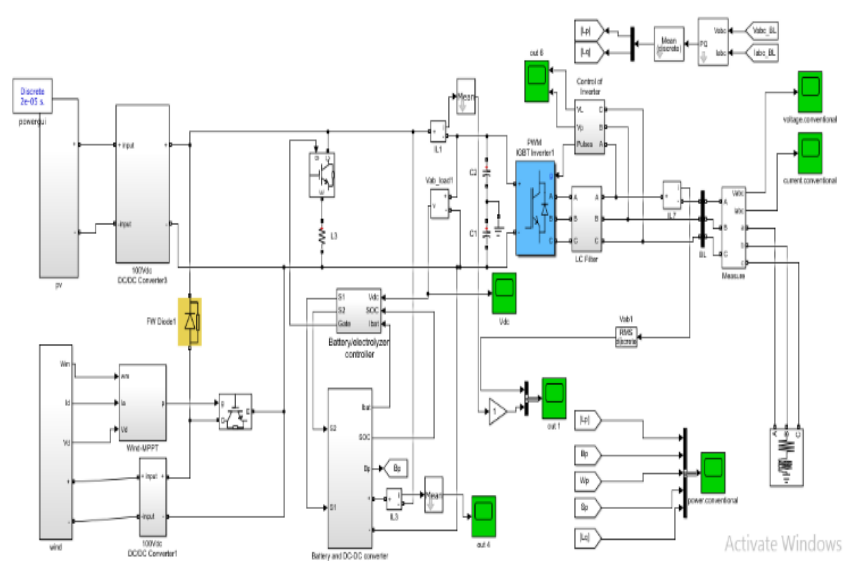

Fig.2.(a).Photovoltaics system for conventional controller
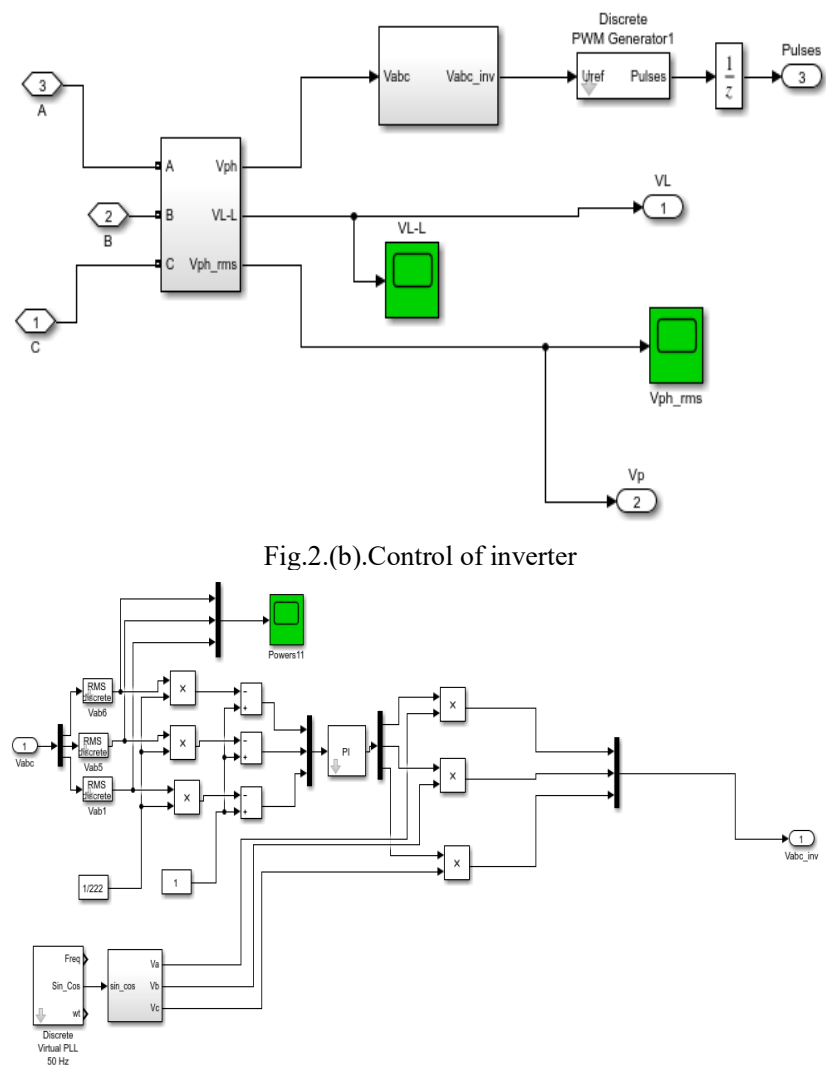

Fig.2.(c).Conventional controller

$$
\begin{aligned}
V_{i a b c} & =L_{i} \frac{d I_{i a b c}}{d t}+R_{i} I_{i a b c}+V_{2 a b c} \\
\frac{d I_{i d}}{d t} & =-\frac{R_{i}}{L_{i}} I_{i d}+\omega I_{i q}+\frac{V_{i d}-V_{2 d}}{L_{i}} \\
\frac{d I_{i q}}{d t} & =-\frac{R_{i}}{L_{i}} I_{i q}+\omega I_{i d}+\frac{V_{i q}-V_{2 q}}{L_{i}}
\end{aligned}
$$

\section{New Proposed Controller}

The MNLC is controlled by the fuzzification, inference system and defuzzification. This controller is based on the membership function and the number of membership control based on the accuracy of the controller [18]. The result produces the membership between the error and change of error.

\section{FL Architecture}

Fuzzification, FRs, Defuzzification processes are the constructing element for FL architecture. The VSC PLL by this FL-PI based IDGC for PV based DG to microgrid is depicted in Fig. 2.a.

\section{Fuzzification}

The VSC dynamic system errors are considered for fuzzification of $K_{p}$ and $K_{i}$ gains prior to system stability limits. The Input $(I P)$ and Output $(O P)$ membership functions are designed according to VSC-PCC dynamic stability limits (Fig. $3)$. The dynamic error $\left(E r_{1}\right.$ and $\left.E r_{2}\right)$ and rate of change in error 
$\left(\partial E r_{1}\right.$ and $\left.\partial E r_{2}\right)$ are considered for present FL $I P$ membership design, where control inputs $\left(\Delta U_{q}\right.$ and $\Delta U_{p}$ for $P_{I}$ and $Q_{I}$ dynamics respectively) are targeted as $O P$ membership. The FL membership constant $L$ is considered $>0$. This $L$ is needed to be optimized further to achieve optimal FL-PI operation under uncertainties (partial shading, islanding etc.).

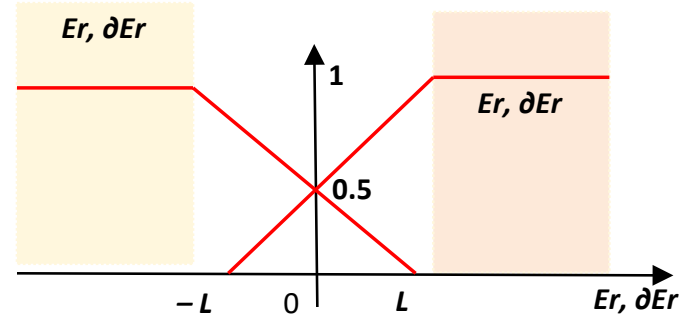

(a)

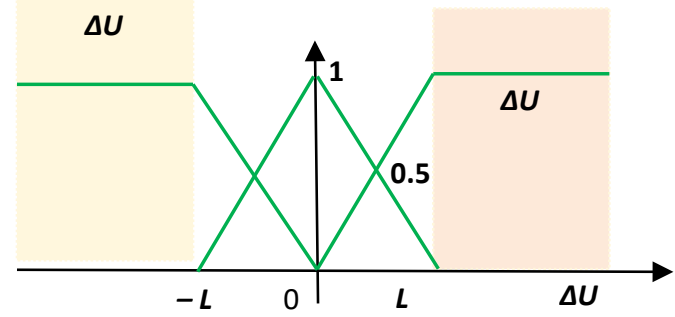

(b)

Fig.3. Membership functions for FL-PI gains: $I P$ and $O P$ membership function

\section{Fuzzy Rule Base}

By using the $I P$ and $O P$ membership (Fig. 3) the following Fuzzy Rules (FRs) are developed for PI gain adaptiveness:

Rule 1. IF $\operatorname{Er}\left(k T_{s}\right)=\operatorname{Er}_{N E G}$ AND $\partial E r\left(k T_{s}\right)=\partial E r_{N E G}$, THEN $\Delta U\left(k T_{s}\right)=\Delta U_{N E G}$.

Rule 2. IF $\operatorname{Er}\left(k T_{s}\right)=\operatorname{Er}_{N E G}$ AND $\partial E r\left(k T_{s}\right)=\partial E r_{P O S}$, THEN $\Delta U\left(k T_{s}\right)=\Delta U_{Z E R}$.

Rule 3. IF $\operatorname{Er}\left(k T_{s}\right)=\operatorname{Er}_{P O S}$ AND $\partial E r\left(k T_{s}\right)=\partial E r_{N E G}$, THEN $\Delta U\left(k T_{s}\right)=\Delta U_{\text {ZER }}$.

Rule 4. IF $\operatorname{Er}\left(k T_{S}\right)=\operatorname{Er}_{P O S}$ AND $\partial E r\left(k T_{S}\right)=\partial E r_{P O S}$, THEN $\Delta U\left(k T_{S}\right)=\Delta U_{P O S}$

The rules are based on the side of membership functions where subscript $P O S \rightarrow$ positive side, $N E G \rightarrow$ negative side, and $Z E R \rightarrow$ zero output. The IF AND THEN based operation is effective as AND is providing minimum tolerance to the FRs. These four rules are considered for PI gains decision.

\section{Defuzzification}

The centroid relationship is implemented for defuzzification of incremental FL control. The IP and OP memberships are further decomposed into 20 IO combinations as depicted in [16]. Finally, the Gains for PI $\left(K_{\text {gain }}: K_{p}, K_{i}\right)$ is calculated as:

$K_{\text {gain }}=\frac{\sum \text { value of IP membershp } \times \text { corresponding OP membeship }}{\sum \text { value of IP membershp }}$

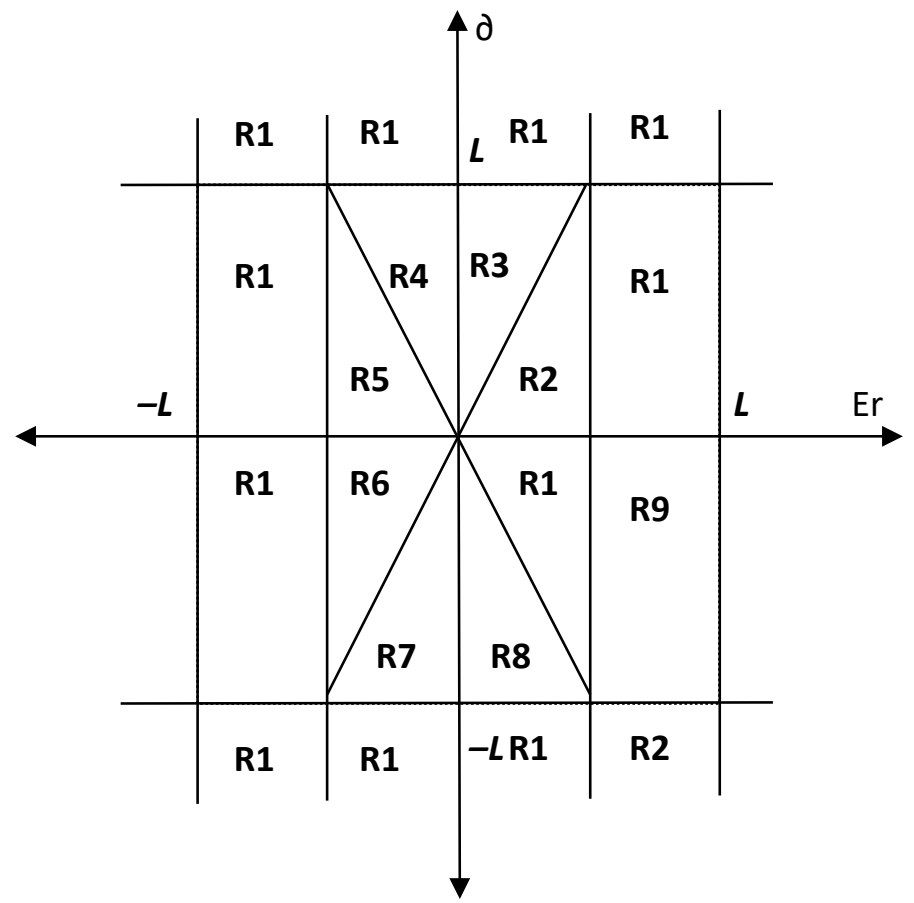

Fig.4. Rule base by combining Er and $\partial \mathrm{Er}$ as $I P$ and $K_{p}$ and $K i$ as $O P$ membership functions

These IO combinations are depicted as FRs in Fig. 4. For present consideration, the error $\left(E r_{l}\right.$ and $E r_{2} \rightarrow$ Fig. 3.a) and rate of change in error $\left(\partial E r_{1}\right.$ and $\partial E r_{2} \rightarrow$ Fig. 3.a) are positioned in horizontal and vertical axes, respectively. These two membership functions overlapped and create a third-dimension representation [16] over two-dimensional membership maps. The upside region of $E r$ is representing [0 to $L$ ] region where the downside is showing $[0$ to $-\boldsymbol{L}]$ region, in two-dimensional plane. The left side and right side of $\partial E r$ are showing [0 to $-\boldsymbol{L}]$ and $[\boldsymbol{0}$ to $\boldsymbol{L}]$ planes of two-dimensional error mapping. The third dimensional membership functions for $K_{p}$ and $K_{i}$ gains are obtained from rule based R1 to R20 as in Fig. 4. The selection of IF THEN rules is implemented as:

$E r=E r_{N E G}$ AND $\partial E r=\partial E r_{N E G}$

THEN $\min (E r, \partial E r)$

For the region IO1 and IO2 the rule R1 can be implemented as:

Step 1. Select the input ( $E r$ and $\partial E r$ ) memberships.

Step 2. Obtain the corresponding output $\left(K_{p}\right.$ and $\left.K_{i}\right)$ memberships.

The $E r$ and $\partial E r$ are obtained from two-dimensional limits as:

$E r_{N E G}=\frac{-E r\left(K \times T_{S}\right)+L}{2 L}$

$E r_{P O S}=\frac{E r\left(K \times T_{S}\right)+L}{2 L}$

and 


$$
\begin{aligned}
\partial E r_{N E G} & =\frac{-\partial E r\left(K \times T_{S}\right)+L}{2 L} \\
\partial E r_{P O S} & =\frac{\partial E r\left(K \times T_{S}\right)+L}{2 L}
\end{aligned}
$$

The final $K_{\text {gain }}$ values can be obtained from defuzzification formulation. The water flow is the basic idea behind this nature inspired algorithm where evaporation, transpiration, condensation, precipitation, and runoff take place to reach a raindrop to sea (optimal point) [18]. Raindrop population is created initially. These are equivalent to PI gains $\left(K_{p, P I}, K_{p, Q I}\right.$ and $\left.K_{i, P l}, K_{i, Q I}\right)$. To minimize the $\operatorname{Er}\left(k T_{s}\right)$ the cost function for proposed optimization problem is derived as:

$f(\phi)=\min \left(\sum_{k=1}^{N_{\text {Tot }}} \sqrt{\left(E r_{1}\left(k T_{s}\right)\right)^{2}+\left(E r_{2}\left(k T_{s}\right)\right)^{2}}\right)$

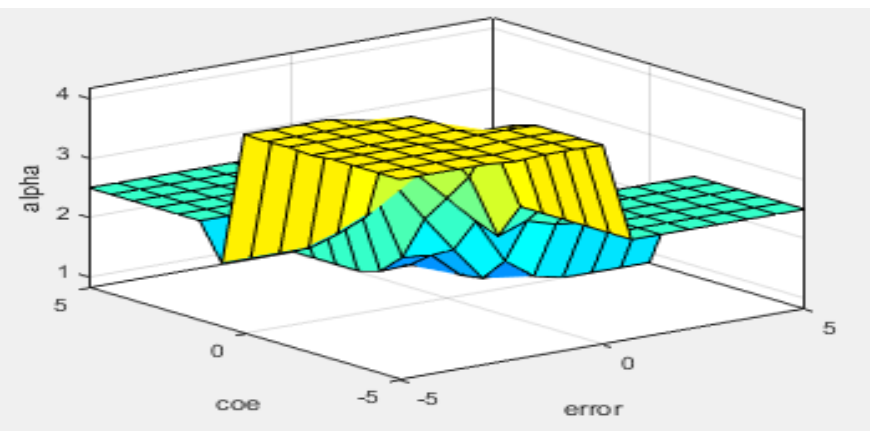

Fig. 5. Rule in surface view

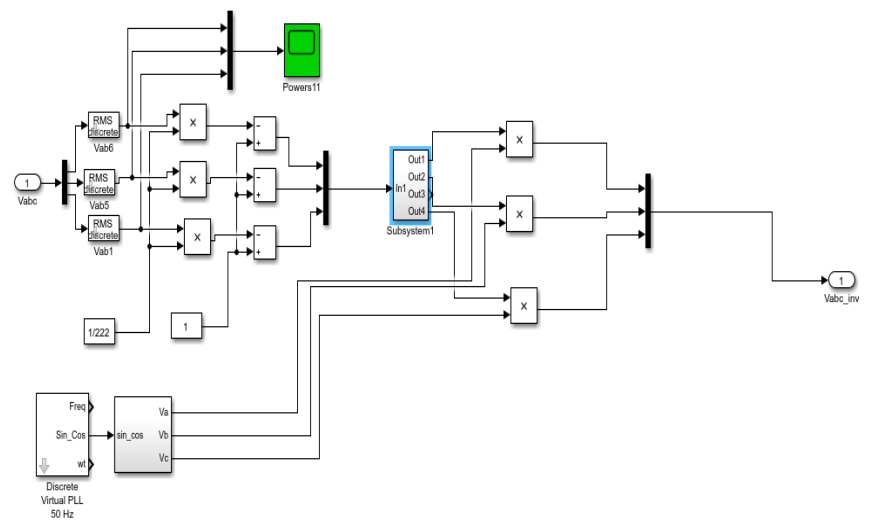

Fig. 6. (a). Subsystem after calculation

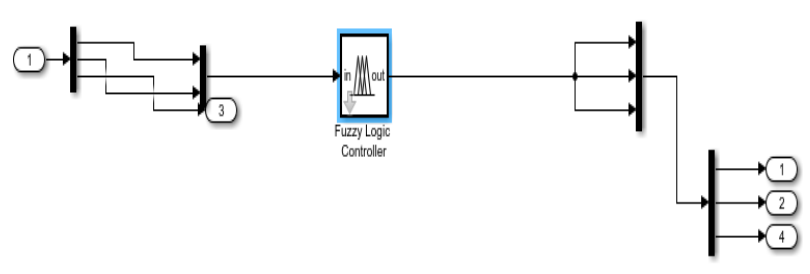

Fig. 6. (b). MNLC

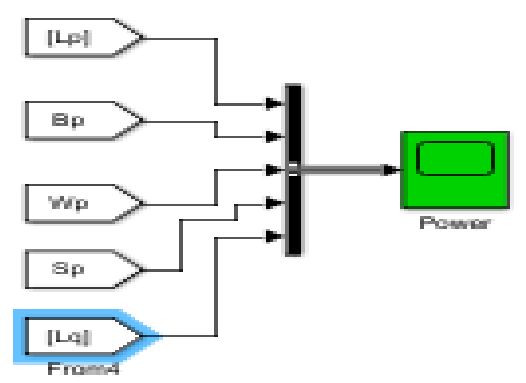

Fig.7.Power scope that shows the result for system

\section{RESULTS AND DISCUSSION}

Fig. 8 shows the difference performance of conventional control and proposed control. The performance is compared under load change during voltage, current, frequency and reactive power. As been showed in the result, proposed control is more stable compare to conventional control during at certain time.

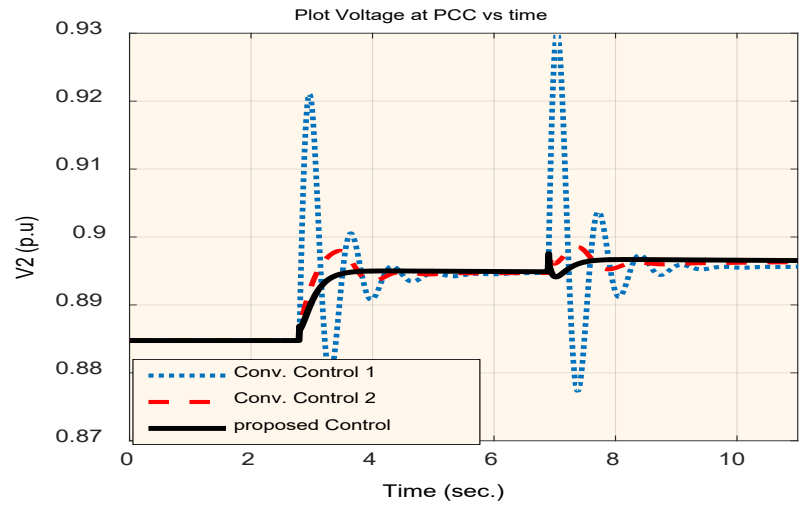

Fig. 8. (a). Voltage performance under load change 


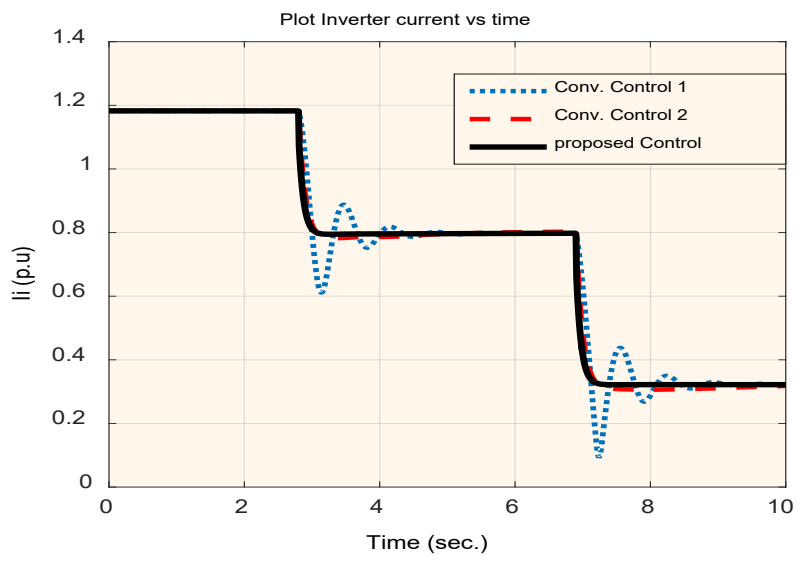

Fig. 8. (b). Current performance under load change

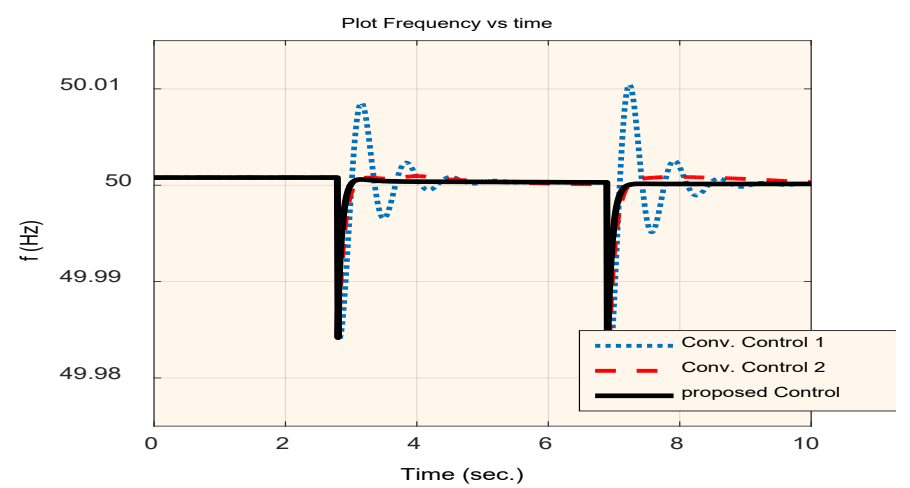

Fig.8. (c). Frequency performance under load change

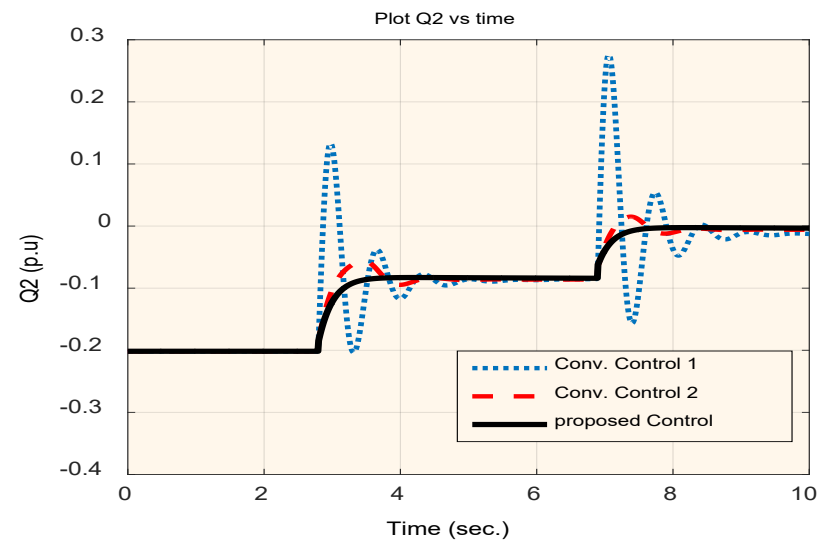

Fig. 8. (d). Reactive power performance under load change

Fig. 9 present that the difference result of performance under partial shading. This scenario is made during $4-6 \mathrm{sec}$ to see that the difference between these two performances. Proposed control is more stable compared to conventional control.

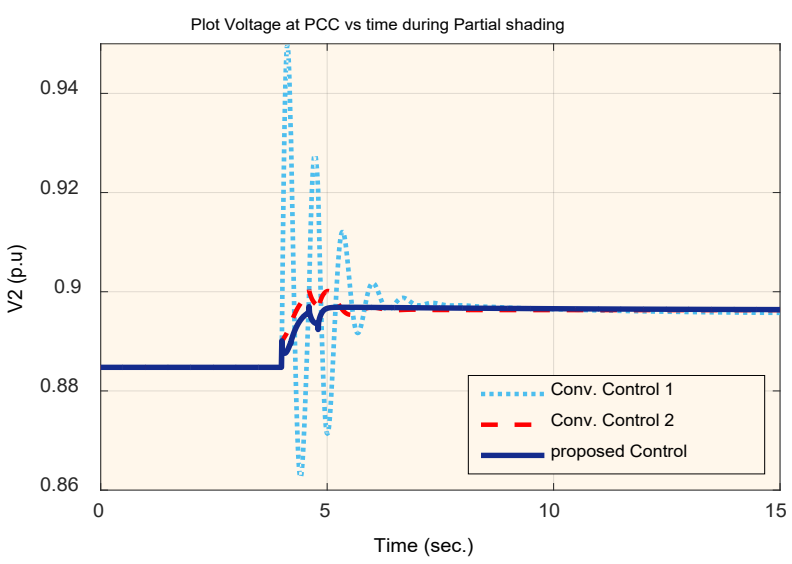

Fig. 9. (a). Voltage performance under partial shading

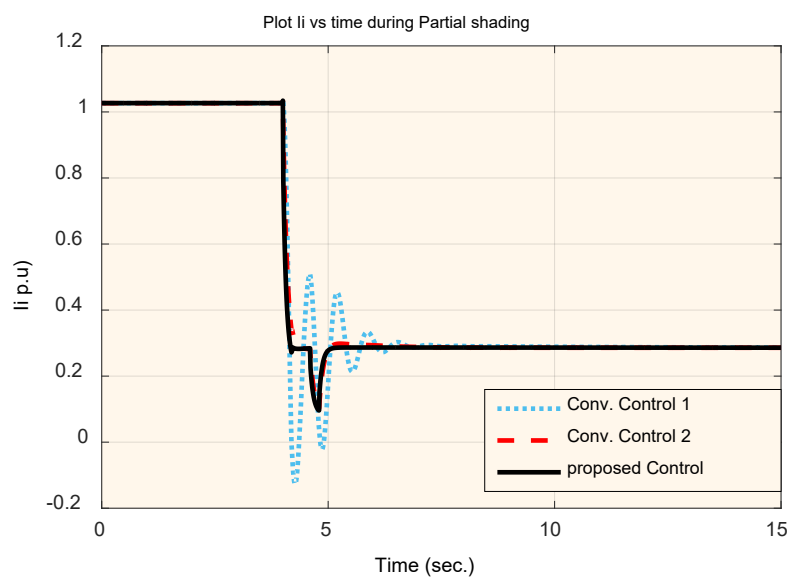

Fig. 9 (b). Current performance under partial shading

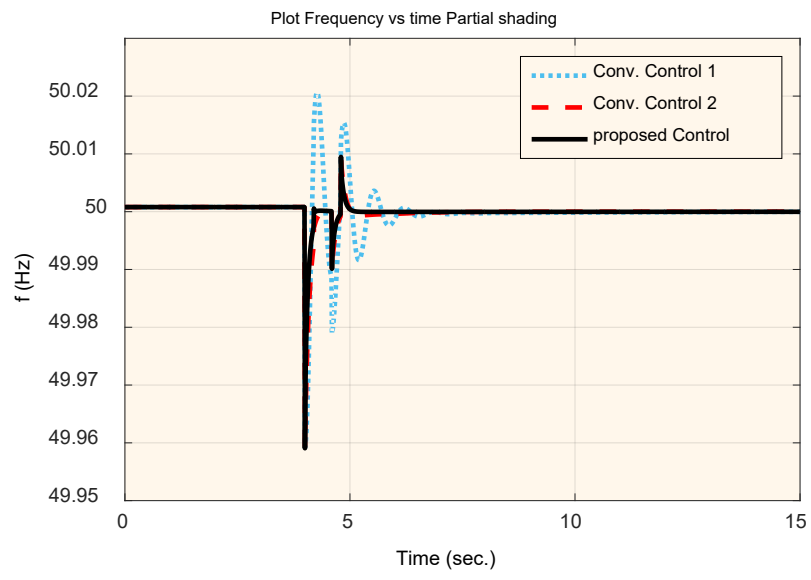

Fig. 9. (c). Frequency performance under partial shading 


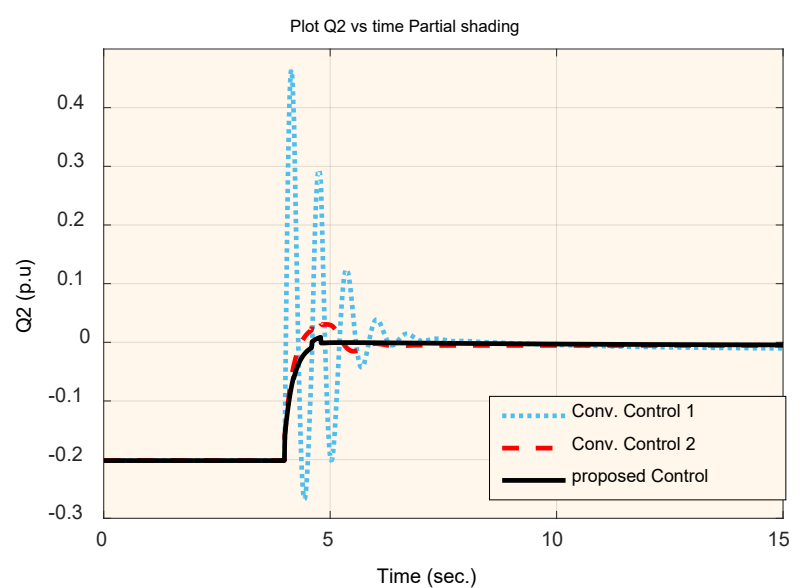

Fig. 9. (d). Reactive power performance under partial shading

Stability performance of MNLC is tested using Bode diagram and Nyquist diagram, it shows in Fig. 10.

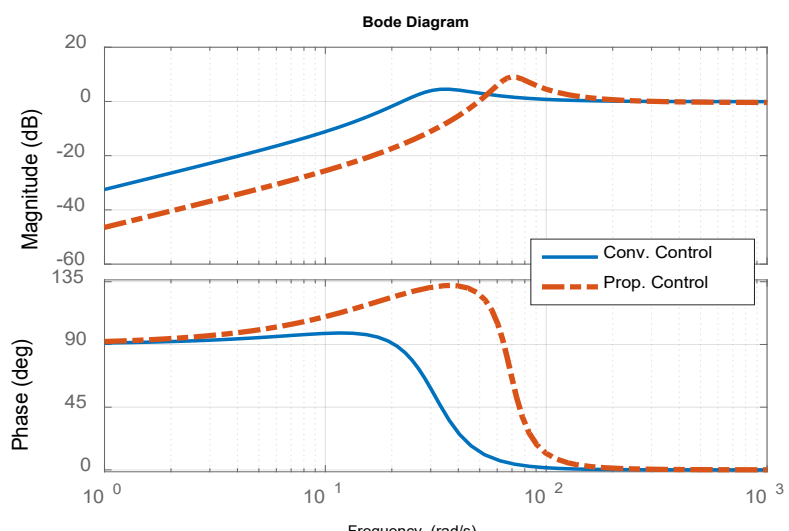

Fig. 10. (a). Bode Plot for small signal stability

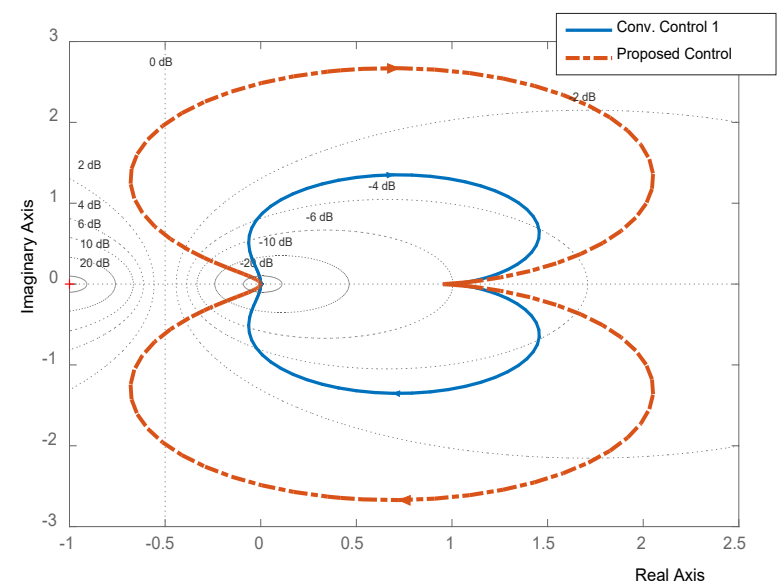

Fig. 10. (b). Nyquist diagram for small signal stability

In proposed Fuzzy-PI control-based feedback path design an adaptive nature is incorporated by metaheuristic algorithm, so that the fuzzy rules are getting adaptive within that same range of error variations.

\section{CONCLUSION}

In proposed Fuzzy-PI control-based feedback path design an adaptive nature is incorporated by metaheuristic algorithm, so that the fuzzy rules are getting adaptive within that same range of error variations. The controller design discussed are incorporated in terms of dynamic behaviour of the Phase Locked Loop/ PLL between converter station and Point of Coupling/ PC (Fig. 2.a). The proposed controller model is obtained in terms of sets of differentials relations in those two sections. The performance validation of such control efficacy is being subjected in terms of small-signal model (Eq. 37, Fig. 8) as well as dynamic oscillation damping (Figs. 6 and 7). The proposed MNLC is quite effective in terms of stability for PV based DG integration for Microgrid applications.

\section{ACKNOWLEDGMENT}

The author and researchers sincerely thank RMC, 600RMC/LESTARI SDG-T 5/3 (188/2019), and UiTM for providing facility and the lecturer to give knowledge conduct this research smoothly.

\section{REFERENCES}

[1] Arunan, J. Ravishankar, and E. Ambikairajah, "Real time stability enhancement for islanded microgrids," in 2017 IEEE Innovative Smart Grid Technologies-Asia (ISGT-Asia), 2017, pp. 1-5

[2] J. M. Carrasco, L. G. Franquelo, J. T. Bialasiewicz, E.Galvan, R. C. P. Guisado, M. A. M. Prats, J. I. Leon, N. M.Alfonso, "PowerElectronic Systems for the Grid Integration of Renewable Energy Sources: A Survey", IEEE Transaction on Industrial Electronics, Vol. 53, No. 4, pp.1002-1016, Aug 2006.

[3] F. Blaabjerg, R. Teodorescu, M. Liserre, A. V. Timbus, "Overview of Control and Grid Synchronization for Distributed Power Genberation System", IEEE Transaction on Industrial Electronics, Vol. 53, No. 5, pp.1398-1409, Oct 2006.

[4] G. Tsengenes, G. Adamidis, "Investigation of the behavior of a three-phase grid-connected photovoltaic system to control active and reactive power", Electric Power Systems Research, 2011, 81, pp.177-184.

[5] A. Timbus, M. Liserre, R. Teodorescu, P. Rodriguez, F. Blaabjerg, "Evaluation of Current Controllers

for Distributed Power Generation Systems", IEEE Trans. Power Electronics, 2009, 24 (3), pp.654-664.

[6] M. F. Schonardie, R. F. Coelho, R. Schweitzer and D. C. Martins, "Control of the Active and Reactive Power Using dq0 Transformation in a Three-Phase Grid-Connected PV System", Int. Conf. on Sustainable Energy, 2012, pp.264-269.

[7] J. E. Garcia, S. Arnaltes, J. L. Amenedo, "Direct power control of voltage source inverters with unbalanced grid voltages", IET Trans. Power Electronics, 2007, 1, pp. 395-407.

[8] Q. Zeng, L. Chang, "An Advanced SVPWM-Based Predictive Current Controller for Three-Phase Inverters in Distributed generation Systems", IEEE Trans. Industrial Electronics, 2008, 55(3), pp.1235- 1246.

[9] X. Bao, F. Zhou, B.Liu, "Feedback Linearization Control of Photovoltaic Inverter with LCL Filter",

Int. Conf. on Power Electronics, and motion control, 2012, pp. 2197-2201.

[10] S. A. Khajehoddin, P. K. Jain,” A Control Design Approach for Three-Phase Grid-Connected 
Renewable Energy Resources", IEEE Trans. on Sustainable Energy,2011, 2(4), pp. 423-432.

[11] J. Hu, L. Shang, Y. He, Z. Q. Zhu., "Direct Active and Reactive Power Regulation of Grid-Connected DC/AC Converters Using Sliding Mode Control Approach", IEEE Trans Power Electronics, 2011, 26 (1), 210-222.

[12] F. Blaabjerg, R. Teodorescu, M. Liserre, A. V. Timbus, "Overview of Control and Grid Synchronization for Distributed Power Generation System", IEEE Transaction on Industrial Electronics, Vol. 53, No. 5, pp.1398-1409, Oct 2006.

[13] Dhar, S., \& Dash, P. K. (2015). A Finite Time Fast Terminal Sliding Mode I-V Control of Grid- Connected PV Array. Journal of Control, Automation and Electrical Systems, 1-22.

[14] A. Tabesh,R. Iravani., "Multivariable Dynamic Model and Robust Control of a Voltage-Source Converter for Power System Applications", IEEE Trans Power Deliv., 2009, 24 (1), pp. 462471

[15] J. M. Maciejowski, "Multivariable Feedback Design”, Reading, MA: Addison- Wesley, 1989.

[16] K. Singhvi, "DEVELOPMENT OF OPTIMAL MPPT TECHNIQUE,” pp. 1-108, 2013.

[17] G. Yajuan, W. Weiyang, G. Xiaoqiang, and G. Herong, “An improved droop controller for grid-connected voltage source inverter in microgrid," in 2nd International Symposium on Power Electronics for Distributed Generation Systems, PEDG 2010, 2010, pp. 823-828

[17] A. Gautam, "Review of Fuzzy Logic Applications in Performance Enhancement of Solar Based Power System.," vol. 8, no. 2, 2015

[18] Kumar, Sanjay, Arun Kumar Verma, Ikhlaq Hussain, Bhim Singh, and Chinmay Jain. "Better control for a solar energy system: using improved enhanced phase-locked loop-based control under variable solar intensity." IEEE Industry Applications Magazine 23, no. 2: 24-36, (2017).

[19] Rezkallah, Miloud, Abdelhamid Hamadi, Ambrish Chandra, and Bhim Singh. "Real-time HIL implementation of sliding mode control for standalone system based on PV array without using dump load." IEEE Transactions on Sustainable Energy 6, no. 4: 1389-1398, (2015).

[20] Zhu, Yunkai, and Juntao Fei. "Disturbance observer based fuzzy sliding mode control of PV grid-connected inverter." IEEE Access 6: 21202-21211, (2018).

[21] Dhar, Snehamoy, and P. K. Dash. "Harmonic profile injectionbased hybrid active islanding detection technique for PV-VSCbased microgrid system." IEEE Transactions on Sustainable Energy 7, no. 4: 1473-1481, (2016).

[22] Sankar, R. S., S. V. Kumar, and G. Mohan Rao. "Adaptive Fuzzy PI Current Control of Grid Interact PV Inverter." International Journal of Electrical \& Computer Engineering (2088-8708) 8, no. 1 (2018).

[23] Sukumar, Shivashankar, Marayati Marsadek, Agileswari Ramasamy, Hazlie Mokhlis, and Saad Mekhilef. "A fuzzy-based PI controller for power management of a grid-connected PVSOFC hybrid system." Energies 10, no. 11: 1720, (2017).

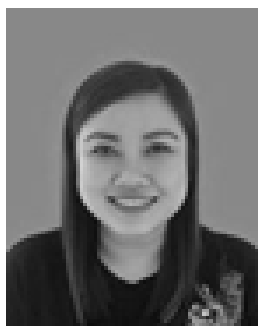

Sharon Serenade Anak Gerang was born in Limbang, Sarawak, in 1994. She obtained Diploma of Electrical Engineering (Electronics) in 2015 Bachelor of Electrical Engineering at Universiti Teknologi Mara, Shah Alam Malaysia in 2018. She is currently studying for Master of Science (Electrical Engineering) at Universiti Teknologi Mara, Shah Alam and doing research focusing on Solar PV in Microgrid Power System.

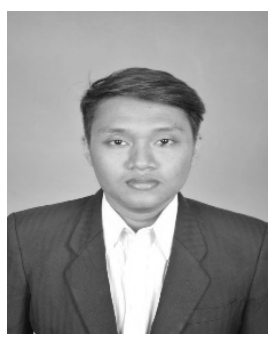

Muhamad Amirul Bin Osman graduated from Universiti Teknologi MARA (UiTM), Malaysia in 2017 with a Bachelor of Engineering in Electrical Engineering. His research is directing on Solar (PV) controllers.

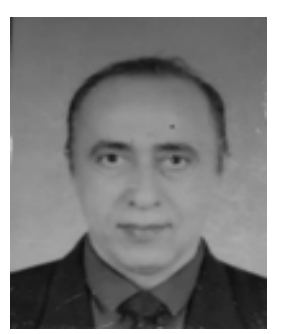

Professor Madya Dr. Naeem M.S. Hannoon (BSc Distinction, MSc, PhD, IEE, IASTED) has over 20 years' experience in both academic and industrial lines. He Worked as Electrical Engineer for 5 years in Kuwait Thermal Power Plant and 2 years as a site engineer in Malaysia and participated in various projects of designing and commissioning of power Substations. Dr Naeem is currently attached to Faculty of Electrical Engineering in University Technology Mara, Malaysia. 